\title{
A CIDADE MURADA: INTERDIÇÃO E MEDO
}

\section{The walled city: interdiction and fear}

\author{
Liliane Vasconcelos \\ Universidade Católica de Salvador (UCSAL).
}

Informações do artigo

Recebido em 22/08/2020

Aceito em 18/og/2020

doi>: https://doi.org/10.25247/2447-861X.2020.n251.p639-657

Esta obra está licenciada com uma Licença Creative Commons Atribuição 4.0 Internacional.

Como ser citado (modelo ABNT)

VASCONCELOS, Liliane. A cidade murada: interdição e medo. Cadernos do CEAS: Revista Crítica de

Humanidades. Salvador/Recife, v. 45, n. 251, p. 639-657, set./dez., 2020. DOI: https://doi.org/10.25247/2447861X.2020.n251.p639-657

\section{Resumo}

O trato, a convivência com o concidadão parecem ter se exaurido do cotidiano das cidades contemporâneas, pelo simples fato de o pacto de convívio ter entrado em declínio, ou praticamente ter se desajustado da proposta inicial da cidade, uma vez que a sociabilidade com o diferente se reduz na mesma medida em que aumenta o distanciamento do Outro. Nesse sentido, o trabalho busca analisar as imagens de convivência presentes na cidade de Salvador, representadas pela literatura e pelo cinema contemporâneo, que trazem no cerne da narrativa os espaços da cidade contemporânea e a relação dos personagens com eles. Como forma de expressar esse fenômeno ou até mesmo de buscar tornar os muros imaginários mais visíveis é que as narrativas $A$ rainha do cine Roma de Alejandro Reis (2010), Salvador negro rancor de Fábio Mandingo (2011), Ó pái, ó de Monique Gadenberg (2007) e Estranhos de Paulo Alcântara (2009) representam Salvador, a partir dos seus medos e enclaves contemporâneos. A fim de alcançar esse resultado, este trabalho elege a mirada dos Estudos Culturais, que investem nos diversos contextos da cidade enquanto texto, bem como em uma ótica multidisciplinar, alicerçada nos estudos urbanos. A pesquisa permitiu identificar, nas obras, que a solidariedade e os afetos humanos presentes nos espaços públicos da Cidade são diariamente sufocados por crueldade, miséria e barreiras à ampla convivência entre os diversos segmentos da sociedade.

Palavras-Chave: Cidade contemporânea. Convivência. Representação. Literatura. Cinema.

\section{Abstract}

The deal, the coexistence with the fellow citizen seems to have been exhausted from the daily life of contemporary cities, due to the simple fact that the cohabitation pact has gone into decline, or practically misfits the initial proposal of the city, since sociability with the different reduces to the same extent that the distance from the Other increases. In this sense, the work seeks to analyze the images of coexistence present in the city of Salvador, represented by literature and contemporary cinema, which bring to the heart of the narrative the spaces of the contemporary city and the relationship of the characters with them. As a way to express this phenomenon or even to try to make the imaginary walls more visible, the narratives $A$ rainha do Cine Roma by Alejandro Reis (2010), Salvador negro rancor by Fábio Mandingo (2011), Ó Pái, Ó by Monique Gadenberg (2007) and Estranhos de Paulo Alcântara (2009) represent Salvador, based on their contemporary fears and enclaves. In order to achieve this result, this work chooses the look of Cultural Studies, which invests in the different contexts of the city as a text, as well as in a multidisciplinary perspective, based on urban studies. The research made it possible to identify, in the works, that the solidarity and human affections present in the public spaces of the City are daily suffocated by cruelty, misery and barriers to the wide coexistence between the different segments of society.

Keywords: Contemporary city, Coexistence. Representation. Literature. Movie. 


\section{Introdução}

O cenário urbano atual das cidades brasileiras é marcado por uma erupção de contrastes socioeconômicos que emanam no seu cotidiano, percebemos, contudo, que as diferenças e os afrontamentos entre ricos e pobres, próximos e diferentes contribuem para que cada vez mais aumentem na cidade a intolerância, o individualismo, a violência e a insegurança nos espaços públicos das metrópoles, tais como na capital baiana.

Ainda que possamos observar um convívio mínimo entre os grupos sociais ou uma suposta urbanidade em Salvador, notamos que as barreiras e interdições se sobrepõem a essas relações. O trato, a convivência com o concidadão parecem se exaurir no dia a dia da capital baiana, pelo simples fato de o pacto de convívio ter entrado em declínio, ou praticamente ter se desajustado da proposta inicial da cidade, uma vez que a sociabilidade com o diferente se reduz na mesma medida em que aumenta o distanciamento do Outro.

Neste contexto, os muros e as barreiras, visíveis ou não, aparecem destacados na paisagem atual que representa Salvador nas narrativas contemporâneas. A fim de balizar o estudo, tecemos como objetivos: "Verificar como as narrativas selecionadas constroem a representação urbana de Salvador na contemporaneidade, e discutir como as linguagens literárias e cinematográficas promovem uma reflexão acerca das relações das personagens com os espaços descritos nas obras como instituidores do imaginário social de Salvador." Sem perder de vista, é claro, que as imagens da cidade contemporânea colaboram para se pensar a crise do urbano e da urbanidade.

A capital baiana, de acordo com a teoria dominante, foi fundada em 1549 e já possuía traçado urbano original, que se reduzia a uma praça, da qual partiam ruas longitudinais e transversais. Era fechada por duas portas: a do sul, Porta de Santa Luiza, na altura do antigo prédio da Secretaria da Agricultura e Viação, hoje Palácio dos Esportes; e a do norte, Porta de Santa Catarina, no começo da Rua da Misericórdia. À medida que foi crescendo, a cidade rompeu o primeiro muro, avançou com a porta do sul até a atual área de São Bento, e a do norte se mudou para a direção do Carmo, situando-se mais especificamente no meio da ladeira do Pelourinho, sendo o acesso denominado de Portas do Carmo.

"Os descobridores portugueses eram homens do Renascimento, mas como urbanistas pertenciam ainda à Idade Média." (SMITH, 1969, p. 28). De fato, como afirma Robert Smith, o sistema de construção da cidade, o arruamento e o local em que foi 
construída representam o tipo de cidade medieval, estruturada sob a eminência da fortificação. A tradição de cidade alta e baixa obedecia ao padrão de construção urbana trazido pelos colonizadores portugueses para o Novo Mundo. A edificação de capelas e fortes também correspondeu a esse tipo de concepção portuguesa, de criar as cidades obedecendo a princípios que regiam fortalezas e centros administrativos de poder.

De acordo com este modelo, historicamente, os muros citadinos eram peça- -chave na concepção da cidade, tanto para marcar fronteiras, como fortificação contra os inimigos exteriores à cidade, como para marcar poder, hierarquias sociais, status de classe nos seus espaços internos. A segregação, desse modo, é uma das características que sempre existiu na urbe. As regras que a organizam apenas se modificaram culturalmente e socialmente de acordo com o tempo, ordenando as estruturas e ações em seus espaços públicos.

Se retornarmos ao século XIX, como nos lembra Kátia Mattoso (1992), a Cidade Alta era onde se localizavam os bairros residenciais arejados por jardins e praças, onde se erguiam muitos edifícios públicos, conventos e igrejas. Esses bairros eram divididos em cinco paróquias (Sé, Santo Antonio Além do Carmo, Santana, São Pedro Velho e Paço), locais onde se concentrava a população baiana, desde burgueses e nobres até artesãos, escravos, alforriados, funcionários, enfim, toda parte da estrutura social baiana, vivendo lado a lado em um caldeamento social intenso.

Nesse quadro social, o que predominava era a categoria social intermediária, o burguês, representado pelos profissionais liberais e pelos comerciantes. Já a parte baixa da cidade era o local de concentração do comércio, frequentado, em sua maioria, por pequenos e médios comerciantes, profissionais livres, negros e negras, pobres que vivenciavam um espaço abafado, malcheiroso e sujo, considerado por muitos viajantes, à época, como lugar de desordem da capital baiana. Esta configuração veio a se modificar com as transformações ocorridas na cidade, sobretudo em função do crescimento populacional e das transformações urbanas.

Até aqui, não há novidade, haja vista que a capital baiana já nasceu imersa num cotidiano urbano marcado por contrastes entre ricos e pobres, negros e brancos, homens e mulheres, Cidade Alta e Cidade Baixa. Como informa Delphine Sangodeyi-Dabrowski (2003, p. 166), 
[...] a segregação em Salvador é intrinsecamente ligada à noção de colonização pela Europa, uma vez que, na concepção do "outro", a diferença toma a similaridade do que não pode ser "semelhante", condição essencial para integração na comunidade citadina.

Hoje, Salvador, além dessa topografia de alto e baixo, se apresenta também por meio de centros e periferias, ou seja, muros visíveis e invisíveis que coexistem nos espaços e que ganharam uma nova forma de representação, chamada "enclaves fortificados". Porém, devido ao fato de ser Salvador uma velha cidade, as pessoas mais pobres habitam, além da periferia, as encostas próximas aos bairros resididos pelas classes média e rica. Esta distribuição socioespacial parece dar a impressão de que, em Salvador, as classes convivem espacialmente juntas; todavia, as barreiras, impostas pela hierarquia social, estão bem demarcadas no seu cotidiano.

Como forma de expressar esse fenômeno ou até mesmo de buscar tornar os muros imaginários mais visíveis é que as narrativas A rainha do cine Roma de Alejandro Reis (2010), Salvador negro rancor de Fábio Mandingo (2011), Ó pái, ó de Monique Gadenberg (2007), e Estranhos de Paulo Alcântara (2009) representam Salvador, a partir dos seus medos e enclaves contemporâneos. A fim de alcançar esse resultado, este trabalho elege a mirada dos Estudos Culturais, que investem nos diversos contextos da cidade enquanto texto, bem como em uma ótica multidisciplinar, alicerçada nos estudos urbanos. Compondo o corpus que delimita o alcance desta investigação, foram escolhidas algumas narrativas literárias e cinematográficas, datadas do século XXI.

No romance de Alejandro Reyes, A rainha do Cine Roma (2010), a história transcorre na cidade contemporânea de Salvador, ou melhor, em um corpo marcado por sinais que remetem aos tempos pretérito e presente: desde a Salvador envelhecida, vista por meio das marquises dos velhos casarões, das velhas igrejas, dos monumentos (que conjugam os tempos), até a ausência dos trilhos, a multiplicação de semáforos, a verticalização das edificações, a multiplicação dos shoppings, enfim, a pluralidade de espaços da urbe contemporânea. O romance apresenta uma Salvador marcada por fome, miséria, violência e intolerância para com os que estão em situação subalternizada, a cidade a partir de personagens em condições adversas: pobres, meninos/meninas de rua, negros e negras, ladrões, prostitutas, travestis, explorados, exploradores e toda sorte de pessoas marginalizadas. 
Em Salvador negro rancor(2011) de Fábio Mandingo, trata-se de uma coletânea de contos, que flagra as condições sociais e físicas da cidade de Salvador inscrito a partir da modernização ocorrida no Pelourinho, na década de go do século passado. Em uma análise crítica, o autor esboça o processo pelo qual a tez urbana foi remodelada e a condição da gente pobre, em sua maioria negros e negras que foram expulsos do local para habitar as áreas periféricas da cidade.

O perfil da cidade, representada no longa-metragem ó paí, ó, dirigido por Monique Gardenberg (2007), traz a velha cidade atrelada aos símbolos e signos da baianidade, consagrados pelos media que representam o imaginário de Salvador. O espaço do Pelourinho é representado a partir de suas ladeiras de pedras, ruas tortas, casarios antigos como também pela presença de figuras exóticas: negros, mulatas sensuais, poetas, líderes religiosos, macumbeiras, viciados em jogos, baianas de acarajés e outros tipos que caricaturam a cidade rememorada das obras de Jorge Amado.

No filme Estranhos, de Paulo Alcântara (2009), Salvador se mostra ainda mais perversa, a partir dos contrastes da Cidade Alta e da Cidade Baixa. A narrativa se desenvolve ao redor do cotidiano de um cidadão que não tem carteira de trabalho e muito menos emprego. Então, como sobreviver numa cidade que se apresenta tão desigual, diante do caos urbano instaurado por aqueles que tentam a vida pelo meio do trabalho informal? Salvador não se mostra nada caridosa com essas pessoas.

O que há em comum nestas obras, tornando-as adequadas para esta análise, é o fato de localizarem a narrativa no espaço urbano contemporâneo da cidade de Salvador, focalizando, sob diferentes perspectivas, a problemática urbana atual, e trazendo a cidade à cena. Nesse sentido, a pesquisa permitiu identificar, nas obras, que a solidariedade e os afetos humanos presentes nos espaços públicos da Cidade são diariamente sufocados por crueldade, miséria e barreiras à ampla convivência entre os diversos segmentos da sociedade.

\section{Convivência e medo}

A ideia do risco perene do afrontamento e a pulsão pelo evitamento criam muros, barreiras, dispositivos de segurança que distanciam o convívio entre os desiguais nos espaços públicos das grandes cidades do país. Simbolicamente, como lugar da negação e da interdição, os muros também representam uma barreira de intolerância e discriminação para 
com o diferente, seja por uma questão de classe ou por uma questão étnica, gerando enclaves que protagonizam o aumento do preconceito e da exclusão na cidade.

Rompeu-se com a estrutura antiga para dar lugar a uma cidade espraiada, verticalizada, de fluxos viários extensivos, segmentada por diversos usos, múltiplas funções e conteúdos sociais distintos. Bairros pobres justapostos a bairros de classes mais altas, ocupações informais dividindo espaço com grandes empreendimentos imobiliários, arquitetura e urbanismo moderno marcando a produção desse novo espaço urbano, cada vez mais segregador e excludente dos benefícios públicos. (SOUZA, 2010, p. 80).

Desse modo, percebemos que o fenômeno de segregação parece se atualizar e marcar a convivialidade nos espaços públicos de Salvador, acompanhado, agora, pelo aumento da violência e do medo que imperam na cidade. É nesse sentido que Gey Espinheira (2001) afirma que, na capital baiana, a marginalidade, a exclusão e a violência estão diretamente relacionadas à capacidade de consumo e de capital social, sobretudo o educacional, como também aos campos da cultura e da etnia ${ }^{1}$. O ambiente urbano estaria, assim, direcionando a condição da violência e da intolerância nos espaços públicos citadinos, contribuindo para o aumento da precarização do sentimento de coletividade e do desejo de segurança.

Crescem os espaços de convívio, moradia e consumo para aqueles que podem pagar para estar acompanhado dos iguais, dos tolerantes e dos amigáveis. É posto à venda um suposto idílio de convivialidade e felicidade plena ${ }^{2}$. Estes são espaços homogêneos, ditados pela lógica do condomínio, nos quais os sonhos são possíveis, as posições estão bem definidas e a segurança é garantida, descartando, desta forma, os espaços inóspitos e inseguros, como os antigos centros urbanos, as favelas, os subúrbios violentos e os guetos. É o tempo dos shopping centers, dos condomínios, dos Alphavilles, que podem ser considerados como "enclaves fortificados", como definido por Teresa Caldeira (2000), o novo padrão de segregação das cidades brasileiras, justificado principalmente a partir do medo do crime.

1 Essa relação atinge principalmente os jovens negros e pobres que residem nas periferias de Salvador. A falta de condição urbana favorável e de acesso aos bens culturais são alguns dos fatores que contribuem para inserção da juventude no mundo da marginalidade, em estreita conjunção com os casos de violência e mortes.

2 Trata-se, portanto, de uma lógica de mercado que se aproveita de um estado de insegurança e vende sonhos de proteção máxima. Máxima, mas não absoluta, posto que as gradações de risco nesses espaços diminuem, mas não cessam de existir. 
Vale ressaltar que esses espaços, de maneira invertida, estão associados ao estado de exceção das periferias e favelas, já que restringem e afastam a circulação das pessoas pela urbe. "Não se trata mais de fazer desenvolver os atrasados, mas de localizar e conter o resíduo como pobreza estrutural globalizada." (DUNKER, 2015, p. 68).

A cidade contemporânea parece caminhar para uma crise, para um esgotamento de si, traduzido por muros que cada vez mais delimitam fronteiras e compõem a paisagem urbana. Daí podemos perceber uma negação, sob a forma de mal-estar na aceitação da diversidade: aquilo que seria inerente à própria cidade, hoje se converte em uma ameaça. Nesta guerra de trincheiras, os muros estariam denegando a cidade ou criando territórios outros, nos quais os diferentes não são aceitos - o que acelera significativamente a exclusão dos pobres e marginalizados da sociedade. Muitos estudiosos chegam a pensar esse momento segregador como o tempo das cidades partidas (VENTURA, 1994), o tempo das cidades divididas (FANTINI, 2000), o tempo das cidadelas (PECHMAN, 2014), ou o tempo do mal-estar da condominialização (DUNKER, 2015).

Se, no passado, os muros da cidade eram construídos para proteger os habitantes dos perigos da natureza ou dos ataques dos diferentes - bárbaros e "selvagens", que eram exteriores à cidade - hoje o medo do Outro se traduz cada vez mais em paisagens muradas, barreiras invisíveis, em enclaves que instituem Salvador. Segundo Antonio Risério (2012, p. 303), "as cidades não erguem muros em seus limites exteriores. Os muros são construídos dentro dela. [...] Trincheira de cidadãos se precavendo contra seus concidadãos.".

Assim, a violência, o medo do diferente, a insegurança e o aumento do individualismo parecem colaborar para Salvador ser representada pela cultura do medo ou simplesmente pela ótica de uma cidade murada. Essa realidade se apresenta tanto nas notícias diárias dos jornais 3 , quanto na cidade retratada pelo cinema e pela literatura que apresentam a urbe contemporânea.

A temática da violência sempre fez parte da realidade da cidade. Criminosos, desordeiros e bandidos são figuras reconhecidas como altamente disseminadas; pequenos furtos e roubos são assuntos fáceis nos noticiários e ruas de Salvador. Hoje, no entanto, além

\footnotetext{
3 Pesquisas realizada por uma ONG mexicana classificam Salvador como a décima quarta cidade no ranking das mais violentas do mundo e como uma das capitais mais desiguais do país. (GLOBO, 2018, p. 1).
} 
dessas questões, existe a onipresença do medo e da insegurança, presentes nos espaços públicos da cidade. Essa realidade parece implantar a cultura do medo e o evitamento do Outro, processo que se manifesta em diversos sentimentos citadinos, como frustração, medo, desespero e vingança. Essa situação, que se generaliza nas cidades brasileiras e se transforma em militarização da vida urbana, estimulou o professor Marcelo Lopes Souza a cunhar o termo "fobópole" ${ }_{4}$ para definir o contexto das cidades atuais. Segundo o autor, esse neologismo foi criado numa tentativa de qualificar as cidades a partir da concepção do medo e da crescente insegurança, que edificam fenômenos como o aumento de enclaves defensivos, preventivos ou mesmo ofensivos.

Como forma de expressar esse fenômeno ou até mesmo de buscar tornar os muros imaginários mais visíveis é que as narrativas $A$ rainha do cine Roma, Salvador negro rancor, $O$ pái, ó, e Estranhos representam Salvador, a partir dos seus medos e enclaves contemporâneos.

Ainda que exista a possibilidade de sonhar para aqueles que estão do outro lado do muro, os que não comungam com uma suposta harmonia e fraternidade existentes na comunidade supostamente "feliz" e "protegida" dos condomínios5, percebemos na narrativa A rainha do cine Roma uma Salvador engendrada em suas barreiras, em seus muros, em seus retalhos que, além de limitar, exclui os cidadãos do direito à cidade. Alejandro Reyes representa quem vive desse outro lado do muro, aqueles que sobrevivem das migalhas deixadas pela cidade, que não possuem dignidade, cidadania ou tampouco uma vida segura.

Fugir dessa realidade só é possível no sonho, no mundo da fantasia, quando as crianças que vivem nas ruas superam as barreiras e criam sua autoimagem como de pessoas que têm o poder de consumo, um dos componentes principais para caracterizar a vida na urbe contemporânea. A imposição da materialidade não somente é vista através dos muros, mas é equacionada também por elementos como roupas, carros, tecnologia, etc., que determinam a percepção da vida social de alguns grupos, haja vista que, muitas vezes, a

4 Fobópole é a combinação de dois elementos de composição, derivados das palavras gregas phóbos, que significa medo, e pólis, que significa "cidade" (SOUZA, 2008, p. 9).

$5 \mathrm{O}$ condomínio aqui é simbolicamente representado como um mundo ideal, consumido por aqueles que tem o poder de compra. 
lógica de pertencimento perpassa pela questão do ter, do poder e do consumir. Essa tríade, além de influenciar na dinâmica urbana, determina os códigos de segmentação da cidade.

Disse que a família dela era cheia de grana, tinha uma casa grandona, máquina de lavar roupa e até carro. Disse mesmo que era limusine, e que ela andava pra cima e pra baixo com o motorista, pra ficar tomando sol nas praias todas da ilha, e vinha a Salvador de ferry fazer compras no shopping porque sua mãe só deixava ela usar roupa de grife. [...] Eu disse que era do Rio e que morávamos na cobertura de um prédio de vinte andares, que só comia coisa fina todos os dias e que ia para escola de rico. (REYES, 2010, p. 15).

Esses locais protegidos passam muito longe do cotidiano de crianças que vivem nas ruas de Salvador e enfrentam suas barreiras físicas e imaginárias, além de experienciar, de forma latente, a intolerância e o medo das ruas. Betinho e Maria Aparecida são pessoas que sentiram na pele esses obstáculos e são vítimas da segregação socioespacial, quando não são vulneráveis à própria violência da cidade.

Vida de pivete, vida de meninos de rua. A gente curtia, só fazia o que nos dava na telha e não tinha ninguém pra ficar dizendo o que podia ou não podia fazer. Mas passávamos por muita ruindade. Sempre ligados, sempre de olho pra ninguém fazer alguma merda com a gente, sempre com fome, sujos, fedidos. É coisa. E de tanto o povo ficar tratando a gente como bicho, a pessoa começa a achar que é bicho mesmo, começa a agir como bicho, fazer qualquer besteira sem pensar em mais nada. É o cão. Mas o mais difícil é ficar centrado, não perder a cabeça, não se meter em merda que não dá em nada que preste. É... o diabo é esse: como fazer para não virar bicho. (REYES, 2010, p. 71).

A lógica da indiferença constrói barreiras significativamente visíveis para Betinho e Maria Aparecida que, na condição de crianças de rua, são tratados como os "bichos" da cidade, como um mal que precisa ser evitado, a se manter afastado, do outro lado do muro. As crianças sofrem as consequências da pobreza e da violência e, muitas vezes, são levadas a se distanciar do próprio sentido da cidade e do que é viver em sociedade. A falta de dignidade, das mínimas condições de sobrevivência, estimula o pensamento de se verem e de se sentirem como bichos, o que limita, nesse caso, o acesso e aceitação por parte dos citadinos e da própria cidade.

Para além da pobreza, a presença dessas pessoas está associada à violência, considerada hoje como o grande mal que assola as cidades contemporâneas. Dunker (2015) ressalta que os muros podem estar associados a essas demandas, seja contra a falta (defesa), seja um significado de indiferença do Outro (recusa), uma alegoria de felicidade interna 
(oferecimento), ou simplesmente atuando como uma negação indeterminada de reconhecimento (não é isso). Nesse sentido, a contenda do muro estaria simbolicamente associada aos lugares de poder ${ }^{6}$, que constroem limites e impõem exclusões.

Paralelamente à condição de privilégio, existe uma vida desregrada que nos remete a uma possível ideia de liberdade, desenvolvida pelo descumprimento de regras, ausência de polidez e falta de cuidado para com o próximo. Percebemos um comportamento voltado primariamente para a sobrevivência, associado aos instintos da natureza, no qual as crianças experimentam sentidos para se proteger da floresta7 corrosiva em que se transformaram as ruas de Salvador. O medo de ser devorado por outros dos "monstros" que habitam a cidade aguça a visão e o sentido de autoproteção, para não ser subjugado também como bicho. $\mathrm{Na}$ verdade, o medo seria a condição ${ }^{8}$ necessária para Betinho e Maria Aparecida, nesse contexto, ainda manterem o elo com a vida:

Conseguiu pegar o último São Marcos antes da madrugada, nem cheio nem vazio, um lugarzinho só, como se lhe esperando. Sentou inocente, na moral, mas percebeu de imediato que a mulher ao lado protegeu a bolsa no colo, instintivamente, com medo. [...] Como tremia, a moça, dava quase para sentir o cheiro do seu medo, no nervosismo com que se movia na cadeira, na respiração parada de bicho acuado, as mãos apertadas na bolsa preta de couro. Podia lhe dominar com uma mão só, sem muita violência, e na certa esse medo era por alguma coisa que tinha ali dentro. (MANDINGO, 2011, p. 51).

Mais uma vez a cidade parece ter se transformado numa floresta, onde o receio do desconhecido domina o cotidiano; a impossibilidade da coexistência dos diferentes parece se agravar e aumentar o medo na selva urbana. Na tentativa de conter esse temor, são criadas

6 O muro como lugar de poder é visto pelos grafiteiros como espaço de registro de sua arte, muitas vezes embasada numa demanda de descontentamento com a cidade, mas em outras como inscrição de uma street art. Para Tarcio V., grafiteiro de Salvador, o muro representa um suporte, uma vitrine, ligada ao questionamento do excesso, da falta ou dos conformes da cidade e é justamente o muro como lugar de comunicação, de afirmação, de poder e de comunhão, no sentido de inversão, que ele vê como local para inscrever sua obra. (Entrevista concedida a Autora por telefone em 24 de outubro de 2018).

7 A floresta está associada ao estado de natureza, ao inverso da civilização. Para Marcelo Jasmin (2007), a vida em estado de natureza estaria relacionada ao estado de igualdade, em que nenhum homem seria regido por nenhuma instituição ou por nenhum ordenamento, todos teriam a mesma força física e seriam aptos a matar.

8 O medo advindo do controle espacial muitas vezes constrói fronteiras que determinam a economia da violência. Segundo Marcelo Souza (2008), a depender do tipo de espaço e dos atores envolvidos, o exercício da violência inclui atividades de extorsão, busca de segurança ou manutenção de certos privilégios. 
barreiras invisíveis, como visto no trecho acima, onde a possibilidade do inesperado já não existe, ações que parecem ser cada vez mais frequentes na cidade.

O último ônibus em direção à periferia de Salvador, uma mulher desacompanhada, a chegada de um corpo masculino e o cruzamento de olhares: tensão máxima determina de imediato uma barreira invisível, que, além de construir o obstáculo do espaço, institui uma sensação de violência e medo. Pressupondo esses indicadores, percebemos as ações que, simbolicamente, estão determinadas para os corpos em atuação nos espaços urbanos, no período da noite9. No transporte público, não é a indiferença que cria barreiras, mas a proximidade na qual os corpos estão dispostos que instaura os muros, obedecendo a uma gramática destinada às pessoas no espaço.

Ao corpo feminino desacompanhado estão destinadas as modulações da violência urbana pré-determinada para as mulheres - um ser frágil, sem grandes resistências, descrito na narrativa como fácil de ser cooptado. O corpo masculino, também desacompanhado, atua como suspeito, como o detentor da força e aquele que impõe o medo. Em se tratando de Salvador, não seria difícil perceber que o corpo masculino em questão é um corpo negro. Fabio Mandingo, neste ponto da narrativa, além de narrar a volta para casa dos trabalhadores à noite, desloca o olhar para os sujeitos vistos como vítimas, na situação de insegurança que permeia Salvador. Todos estão em relação de vulnerabilidade perante o olhar suspeito da cidade, ou melhor, sob a ameaça da vasta sombra de receio e desconfiança que se tornou a própria cidade. Na concepção do capitalismo avançado, as paredes físicas se tornaram, mais do que fronteiras que riscam a cidade no intuito de estabelecer a separação dos corpos, a enunciação das demandas do poder econômico. Afora a necessidade de mercado, este poder tem que garantir o acesso dos consumidores aos mercados, lojas, shoppings, bares, a todo o mundo do consumo.

Garantir segurança é um dos principais pontos que regem a lei de mercado em Salvador. O mercado da segurança privada aumentou significativamente nas cidades, legitimando o enclausuramento de determinados grupos sociais e a falência do espaço como

9 Durante muito tempo, os textos clássicos consagraram a noite como o mal a ser evitado, como o período das trevas, das sombras, das almas que vagam. Não é por coincidência que o início da iluminação pública nas cidades está associado à chegada da segurança que afugenta o mal. É provável que o temor da noite ainda perdure por muito tempo, uma vez que a insegurança nos espaços públicos aumenta as agressões noturnas, como afirma Jean Delumeau (2007). 
local de convivência entre os diferentes. Uma vez que o próprio Estado falha na oferta de segurança, consequentemente, percebemos o aumento de segurança privada, de guaritas, de alarmes, de aparatos que garantam o bem-estar e o consumo dos concidadãos.

Por outro lado, observamos também que a ausência do Estado, permitindo a ampliação da violência nas ruas, deslegitima sua própria atuação na vida daqueles que podem pagar por segurança. Interessante perceber que, a partir desses enclaves, a cidade regride, ao ser pensada por meio de separações e controle de fronteiras. Esta configuração parece trazer uma nova forma de pacto social e organização dos espaços, sugerindo, de modo bastante simplista, que a ordem (o bem) estaria voltada para aqueles que têm capital e estão protegidos por muros, ao passo que a desordem, a criminalização (o mal), se destinaria às categorias destituídas de tal poder.

No filme Ó paí, ó, de Monique Gardenberg (2007), Salvador é narrada por diversificados muros visíveis/invisíveis, que representam a segregação na cidade contemporânea. Um desses muros, que interessa discutir aqui, é gerado por enclaves fortificados, que desafiam a cidade e provocam a criminalidade. A contratação de segurança para garantir a presença de clientes e turistas na loja de seu Gerônimo é uma dessas barreiras que enclausuram a cidade em alguns fortes, como os de consumo, o que tragicamente resultará em morte. Vale ressaltar que as desigualdades sempre estiveram presentes nas ruas do Pelourinho ${ }^{10}$; a novidade emblemática representada no longa se refere à ideia de exclusão social, combinada com atos de violência e militarização do cotidiano da cidade.

No antiquário de Seu Gerônimo só são bem-vindos aqueles cidadãos que têm condições mínimas de compra; aos outros, não interessa estar no espaço da loja, construída principalmente para atender a um público especializado. Essa forma de delimitação já demarca a ideia de condominização que caracteriza a cidade: para fazer parte do espaço, é necessária uma espécie de autorização, que, no caso da cena narrada, é dada pelo poder de compra, pelo dinheiro.

\footnotetext{
${ }^{10}$ Tanto a literatura quanto o cinema produzidos no século $X X$ protagonizaram, em suas narrativas, as desigualdades presentes nessa parte da cidade. O Pelourinho, em muitas obras urbanas de Jorge Amado, é narrado como palco da convivência de meninos de rua, prostitutas, capoeiristas, trabalhadores, comerciantes, etc. - ou seja, como palco síntese da cidade da Bahia do período. No cinema, além das muitas adaptações das obras de Amado, como exemplo da temática temos também O pagador de Promessa (1962), dirigido por Anselmo Duarte.
} 
A presença da segurança interna parece já anunciar esse desejo do proprietário, porém, como se trata de um comércio localizado na Ladeira do Pelourinho, o policiamento vigente, oferecido pelo Estado (FIGURA 1, p. 644; FIGURA 2, p. 644), como demonstra Gardenberg, não é suficiente para garantir o acesso de turistas e clientes ao espaço da loja.

Figura 1 - Comércio localizado na Ladeira do Pelourinho,

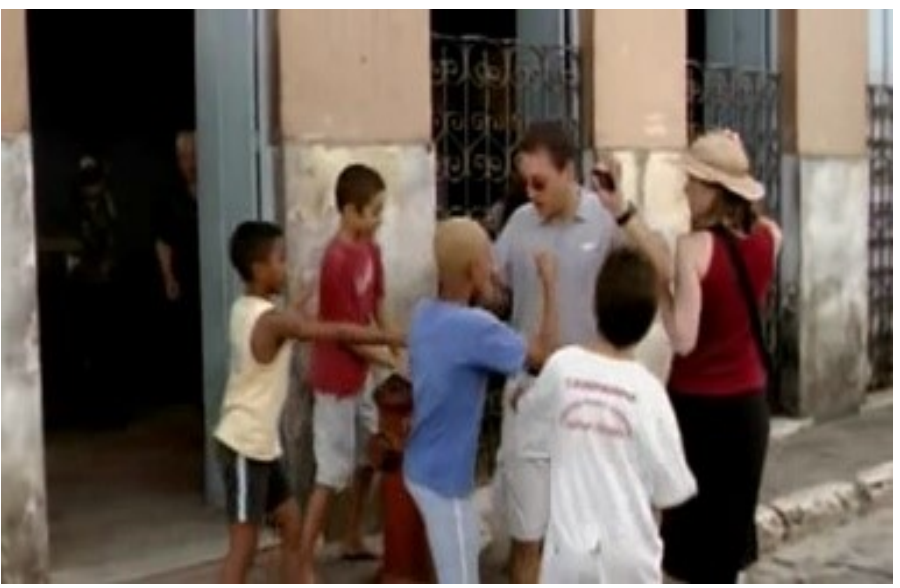

Fonte: Ó PAÍ, Ó. Direção: Monique Gardenberg.

Figura 2- Comércio localizado na Ladeira do Pelourinho,

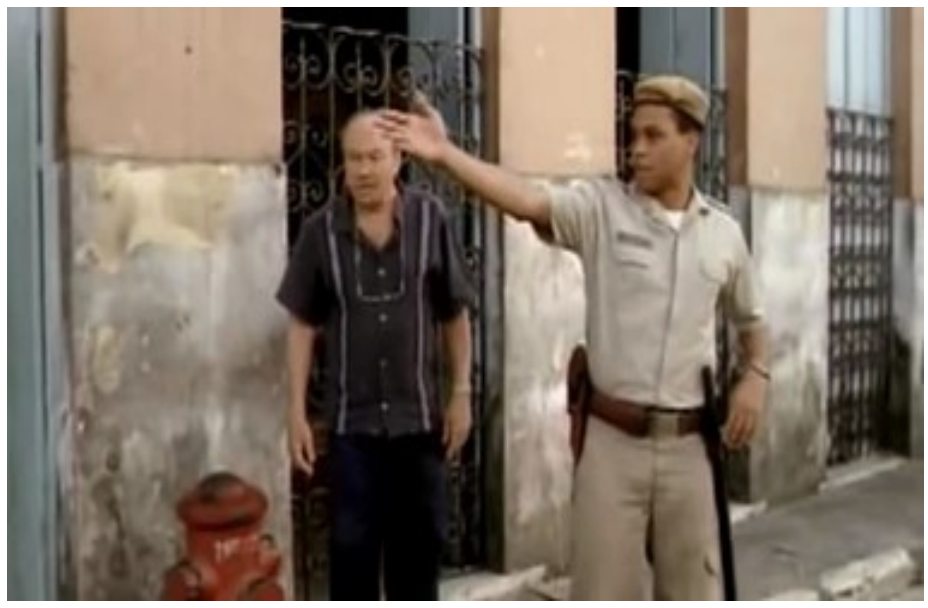

Fonte: Ó PAÍ, Ó. Direção: Monique Gardenberg.

As imagens acima (FIGURA 1, p. 644; FIGURA 2, p. 644) representam 0 desdobramento das ações de meninos de rua, que vivem de traquinagem e pequenos furtos nas ladeiras do Pelourinho; a interceptação de um casal de turistas no espaço externo ao comércio de Seu Jerônimo é um exemplo disso. Para conter as ameaças dessa ordem social que ganha corpo nos espaços públicos e garantir o lucro em suas vendas, o proprietário do 
estabelecimento recorre à contratação de segurança particular para "limpar a área"11, ou seja, banir das ruas e ladeiras do Pelourinho crianças pobres que vivem a importunar a ordem do local. Curiosamente, na cena em questão, a pessoa contratada para servir de segurança da loja é o próprio policial que trabalha salvaguardando as ruas e ladeiras do Pelô. Essa situação, de início, já se torna um problema, tanto para aqueles que podem pagar por segurança, quanto para os cidadãos, que são cotidianamente vítimas da violência e do descaso da segurança pública oferecida em Salvador.

Se pensarmos, como afirma Teresa Caldeiras (2000, p. 10), que "[...] [a] privatização da segurança desafia o monopólio do uso legítimo da força pelo Estado [...]", não é desarrazoado supor que a problemática do risco atinge a todos, uma vez que o estado de insegurança, a omissão do Estado e o olhar direcionado do policial reproduzem um desregramento, uma previsibilidade que condiciona uma relação tênue com a violência. $\mathrm{Na}$ verdade, a proteção e a reação dessas atividades só aumentam o medo, os espaços hostis e a falta de convivialidade na cidade, fatores que se vão adicionando às demandas para construção de muros.

Esse modelo se estende por Salvador e se torna mais latente nos bairros considerados nobres, onde a predominância dos condomínios constrói a paisagem local, imperando espaços homogêneos, lugares bem definidos em que cada pessoa tem os papéis estabelecidos no usos dos espaços, ou seja, aquelas pessoas que não podem pagar por eles têm o seu uso interditado. É evidente, que se trata de uma convivência idealizada e pautada na convivência entre iguais, restando ao diferente barreiras e muros sociais que delimitam e esvaziam a convivência nesses espaços. Assim, no condomínio vive-se "o antigo ideário de modernização como planejamento e modernização como planejamento e antecipação, mas abdicando, então de sua universalidade" (DUNKER, 2015, p. 53). Essa realidade, contribui para percebermos que, cada vez mais, a convivência com a cidade, a sociabilidade nos

\footnotetext{
${ }^{11}$ A expressão "limpar a área", usada pelo personagem Seu Jerônimo, converge com a visão de uma política higienista que ocorreu em Salvador no século XIX, quando era preciso controlar as condições de saúde dos habitantes da cidade, fenômeno sanitário que se ligava estreitamente a condições sociais da existência à época. Em outras palavras, existia uma ideia de vigilância do Estado com relação às formas de moradia, a fim de evitar doenças e epidemias: era preciso higienizar e embelezar a cidade com ares puros e modernos. Hoje esta ideia está atrelada à necessidade dos governantes de afastar dos grandes centros de turismo os pobres e pedintes, com o intuito ainda de embelezar e atrair turistas.
} 
espaços públicos vai se esvaindo e cria-se a cultura do medo de conviver com o diferente, aumentando a segregação socioespacial.

A experiência do medo amplia os enclaves fortificados, demonstrando uma queda significativa dos espaços de convivência e tolerância com o diferente. Com o argumento de que é preciso se proteger do crime, os moradores desses bairros adotam técnicas de segurança cada vez mais sofisticadas: condomínios fechados, conjunto de escritórios, shopping centers, cercas elétricas, tudo mantido no intuito de barrar, identificar e controlar os diferentes que, por acaso, queiram circular por esses espaços. Essa realidade acaba construindo bairros de difícil acesso, totalmente fortificados e consolidados em seus muros. Ressalte-se que todo este aparato de proteção não é garantia absoluta de segurança, muito menos de afastamento da presença da violência da cidade.

Em Estranhos (2009), filme de Paulo Alcântara (FIGURA 3, p. 646; FIGURA 4, p. 647; FIGURA 5, p. 647), a capital baiana é representada a partir dessa perspectiva de cidadela fortificada por muros, na qual a segregação e o processo de ostensiva separação social se cristalizam, mas não afastam a violência.

Figura 3-Cidadela fortificada por muros

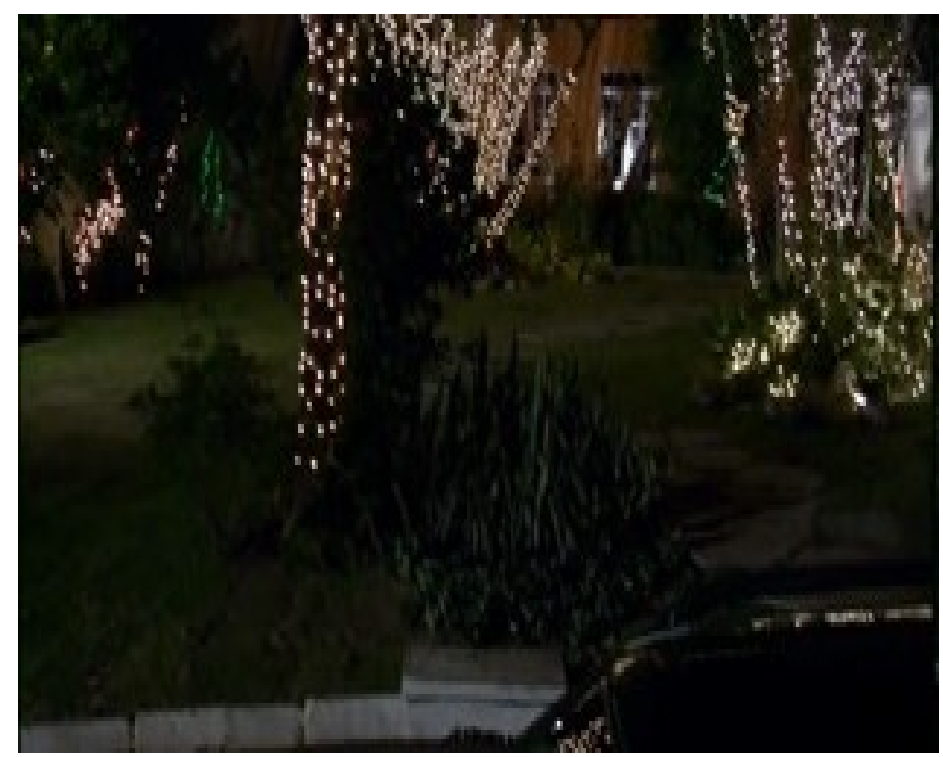

Fonte: ESTRANHOS. Direção: Paulo Alcântara. 
Figura 4 - Cidadela fortificada por muros

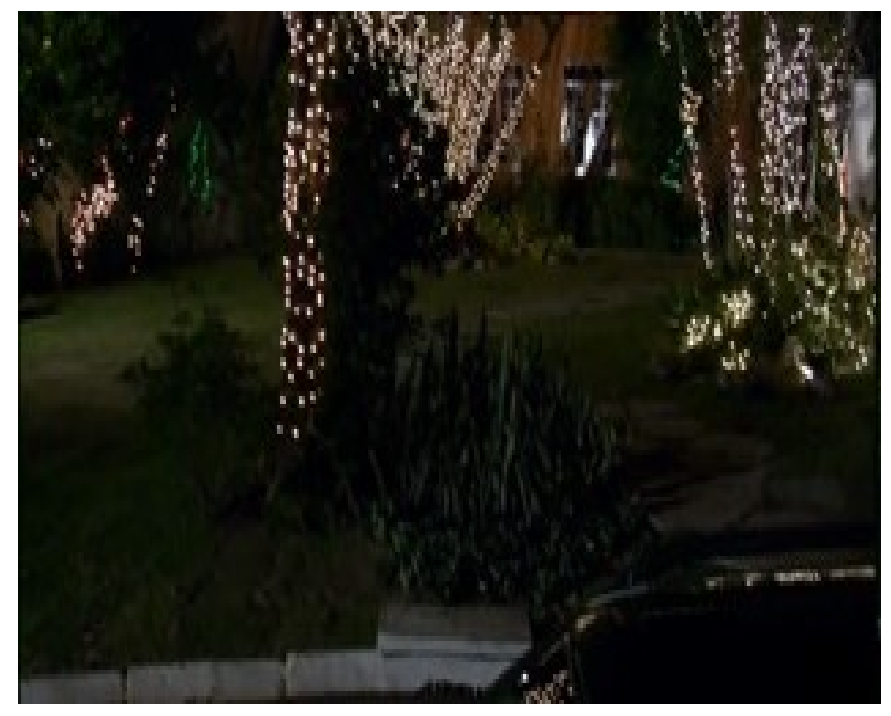

Fonte: ESTRANHOS. Direção: Paulo Alcântara.

Figura 5-Cidadela fortificada por muros

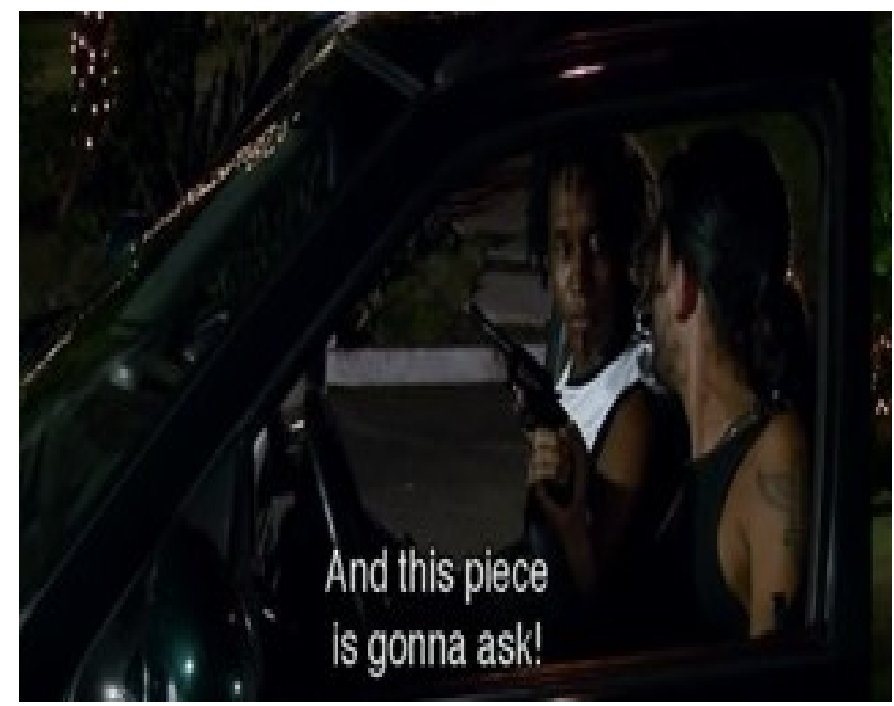

Fonte: ESTRANHOS. Direção: Paulo Alcântara.

Dois amigos, Geraldão e Tonho, que vivem de pequenos furtos pela cidade, resolvem investir mais alto no mundo do crime, acreditando que é preciso ultrapassar determinadas barreiras da cidade para terem um lucro maior com os furtos. Como costumam perambular pelo centro da cidade e pelo subúrbio de Salvador, a investida nos bairros nobres e a falta de conhecimento das barreiras locais acabam por atrapalhar os avanços da tão planejada noite. Violência para nós, espectadores, brutalidade maior para os moradores da mansão escolhida pelos assaltantes, como demonstra as Figuras 4 (p. 647 ), e 5 (p. 647). 
Embora visualizemos uma bela casa, iluminada com luzes de Natal, e um grande jardim sem muros, percebemos tratar-se de um local residido por uma elite econômica que paga para desfrutar de uma suposta sensação de segurança e liberdade. A falta da materialidade de muros e de um vigia facilita a ação dos personagens e parece deixá-los mais livres e seguros para executar o roubo, mas, antes mesmo de chegarem à referida casa, os personagens são abordados por uma viatura da polícia, que patrulha as ruas do condomínio de casas. Há a sugestão da existência de liberdade na convivência com os semelhantes, porém o distanciamento da casa para a rua é o que demarca a distância entre o convívio coletivo e o convívio privativo.

Uma das formas de manter a segurança da casa, além dessa estratégia, é a instalação de um alarme interno para proteção. Esta barreira, num primeiro momento invisível aos olhos invasores, surpreende os atrapalhados assaltantes, levando a noite a um fim trágico, com a morte da jovem moradora. A combinação dessas fortificações que riscam o espaço da cidade, deflagrando cada vez mais a fragmentação do espaço público, como visto aqui, traz o acréscimo de significativas e, por vezes, funestas consequências, dando seu quinhão de contribuição para a falência das relações de convivência na cidade e para o aumento do medo e da violência em Salvador.

\section{Considerações finais}

De acordo com o exposto acima podemos observar que tanto a literatura quanto o cinema produzidos atualmente sobre Salvador traz para o cerne da narrativa a emergência de discutir a problemática urbana das grandes cidades. O medo, a violência, a indiferença com o Outros da cidade são nuances da cidade contemporânea que constroem as textualidades que representam a capital baiana. Mais especificamente, a experiência urbana vivenciada pelos sujeitos das margens: a vida da ralé que se desdobram nas narrativas atuais.

O cenário urbano narrado é apresentado como a possibilidade das incertezas, das faltas e, evidentemente, do sentido único da cidade. A cidade-solidão, a cidade-partida e a cidade-ameaçada podem ser detectadas nas diversas paisagens impressas sobre a capital baiana, na medida em que traduzem em imagens a forma de conduzir Salvador e suas complexidades. É recorrente uma territorialidade que expressa as imagens de espaços hostis e a falta de convivialidade na cidade, fatores que se vão adicionando às demandas para 
construção de muros. Estas barreiras riscam o espaço da cidade, deflagrando cada vez mais a fragmentação do espaço público, como visto aqui, trazem o acréscimo de significativas e, por vezes, funestas consequências, dando seu quinhão de contribuição para a falência das relações de convivência na cidade e para o aumento do medo e da violência em Salvador.

\section{Referências}

CALDEIRA, Teresa. Cidade de muros: crime, segregação e cidadania em São Paulo. São Paulo: Editora 34; São Paulo: Edusp, 2000.

DELUMEAU, Jean. Medos de ontem e de hoje. In: NOVAES, A. Ensaios sobre o medo. São Paulo: Editora SENAC São Paulo, 2007. p. 39-52.

DUNKER, Christian. Mal-estar, sofrimento e sintoma: uma psicopatologia do Brasil entre muros. São Paulo: Boitempo, 2015.

ESPINHEIRA, Gey. Sociabilidade e violência na vida cotidiana em Salvador. Bahia: análise e dados, Salvador, v. 11, n. 1, p. 08-11, jun. 2001. Disponível em: https://goo.gl/QG3b1r. Acesso em: 8 dez. 2019.

ESTRANHOS. Direção: Paulo Alcântara. Produção: Paulo Alcântara e Carla Guimarães. Intérpretes: Jackson Costa; Cyria Coentro; Tom Carneiro; Agnaldo Lopes; Caco Monteiro; Nelito Reis; Angelo lávio; Mariana Muniz; Heduen Muniz e Larissa Libório. Roteiro: Carla Guimarães e Santiago Roncagliolo. [S.I.]: Araçá Azul Cine e Vídeo, 2009. Digital, cor, 101'

FANTINI, Marcia. Cidade dividida: dilemas e disputas simbólicas em Florianópolis. Florianópolis: Cidade Futura, 2000.

JASMIN, Marcelo. O despotismo democrático, sem medo e sem Oriente. In: NOVAES, Adauto. Ensaios sobre o medo. São Paulo: Editora SENAC São Paulo, 2007. p. 111-133.

MANDINGO, Fábio. Salvador negro rancor. São Paulo: Ciclo Continuo; Salvador: Blacktude, 2011.

MATTOSO, Kátia M. de Queiros. Bahia, século XIX. Rio de Janeiro: Editora Nova Fronteira, 1992.

Ó PAÍ, Ó. Direção: Monique Gardenberg. Produção: Augusto Casé; Paula Lavine e Sara Silveira. Intérpretes: Lázaro Ramos; Dirá Paes; Wagner Moura; Stênio Garcia; Luciana Souza; Emanuelle Araújo; Rosa Jamille Alves; Cidnei Aragão; Yolanda Merry Batista; Érico Brás; Ednalva Carvalho; Mateus Ferreira da Silva; Felipe Fernandes; Natalia Garcia e outros. Roteiro: Bettine Silveira; Dudu Miranda; Márcio Meirelles e Monique Gardenberg. Rio de Janeiro: Globo Filmes; Dueto Filmes; Dezenove Som e Imagens; Natasha Filmes, 2007. 1 DVD. 
PECHMAN, Robert M. Por que Simmel? In: PECHMAN, Robert M. (Org.). A pretexto de Simmel: cultura e subjetividade na metrópole contemporânea. Rio de Janeiro: Letra Capital, 2014.

REYES, Alejandro. A rainha do Cine Roma. São Paulo: Leya, 2010.

RISÉRIO, Antonio. A cidade no Brasil. São Paulo: Editora 34, 2012.

SANGODEYI-DABROWSKI, Delphine. As raízes ideológicas da segregação no Brasil. In: ESTEVES JUNIOR, Milton; URIARTE, Urpi Montoya (Orgs.) Panoramas urbanos: reflexões sobre a cidade. Salvador: EDUFBA, 2003.

SMITH, Robert. Arquitetura civil no período colonial. Revista do Patrimônio Histórico e Artístico Nacional, Rio de Janeiro, n. 17, p. 27-125, 1969. Disponível em: http://goo.gl/PfTqZe. Acesso em: 6 dez 2019.

SOUZA, Angela Gordilho. Ocupação urbana e habitação. In: BAHIA. Centro antigo de Salvador: plano de reabilitação participativo. Salvador: Secretaria de Cultura; Salvador: Fundação Pedro Calmon, 2010. p. 72-102.

SOUZA, Marcelo Lopes de. Fobópole: o medo generalizado e a militarização da questão urbana. Rio de Janeiro: Bertrand Brasil, 2008.

VENTURA, Zuenir. Cidade partida. São Paulo: Companhia das Letras, 1994.

\section{Detalhes da autora}

Liliane Vasconcelos

Doutorado em Letras (Literatura Brasileira), pelo programa de Pós-graduação em Literatura e Cultura da Universidade Federal da Bahia, UFBA, (2016). Doutorado Sanduíche no Programa de Pós- Graduação do Instituto de Pesquisa e Planejamento Urbano e Regional da Universidade Federal do Rio de Janeiro, IPPUR/UFRJ (2015). É professora da Graduação em Letras, professora colaboradora do Programa de Pós-Graduação em Planejamento Territorial e Desenvolvimento Social da Universidade Católica do Salvador e da Rede Pública do Estado da Bahia. Atualmente é coordenadora e professora do Centro de Escrita Científica da Universidade Católica do Salvador e líder do grupo de pesquisa Temporalidades Urbanas. Tem experiência na área de Letras, com ênfase em Literatura Brasileira, atuando principalmente nos seguintes temas: Literatura Brasileira, Literatura Baiana, Imaginário Urbano. E-mail: lilianelilivj@gmail.com ORCID: https://orcid.org/0000-00024399-7109 